\title{
Comparison of periodontal parameters and metabolic glucose levels in patients with diabetes and healthy subjects
}

\author{
Bateni E, DDS, MS ${ }^{1}$, Rabiei A, DDS, MS ${ }^{2}$, Ghanbarzadegan A, Dentistry Student ${ }^{3^{*}}$ \\ 1- Assistant Prof., Dept. of Periodontology, Rafsanjan University of Medical Sciences, Rafsanjan, Iran. 2- General Dentist, \\ Rafsanjan, Iran. 3- Dentistry Student, Student Research Committee, Rafsanjan University of Medical Sciences, Rafsanjan, \\ Iran; Dentistry Student, Clinical Research Development Center, Ali ebn Abitaleb Hospital, Rafsanjan University of Medical \\ Sciences, Rafsanjan, Iran
}

\begin{abstract}
Received: November 2016, Accepted: December 2016

Background: For decades, it was suspected that diabetes contributed to poorer oral health and the increased frequency of periodontitis. More recently it was found that periodontitis could adversely affect glycemic control in diabetics. The aim of this study was to compare periodontal parameters with the metabolic sugar levels of diabetic and non-diabetic individuals.

Materials and Methods: In this cross-sectional study the experimental group were individuals with the diagnosis of diabetes. The control group consisted of healthy individuals without any systemic condition that affected periodontal status. Periodontal parameters, body mass index, HbAlc level and duration of diabetes were measured and recorded. Data were analyzed using Pearson's correlation coefficient and Spearman's correlation coefficient in a bivariate normal distribution.

Results: Patients with diabetes had worse periodontal status compared with control group. On the other hand, both patients with diabetes type 1 and 2 showed higher plaque index, bleeding index and clinical attachment loss compared with healthy control group. There was no meaningful relation between $\mathrm{HbA} 1 \mathrm{c}$ and periodontal indices. In type 2 diabetic individuals, there was a significant correlation between the number of missing teeth and the duration of their illness.

Conclusions: Based on the evaluated parameters in this study, the experimental groups, (type 1 and 2 diabetics), experienced worse conditions than healthy control individuals with respect to their periodontal status. Deterioration of periodontal status is directly related to diabetes progression.
\end{abstract}

Keywords: Periodontitis, Diabetes Mellitus, $\mathrm{Hb}$ A1c, Glycemic

\section{Introduction}

Periodontitis is one of the most ubiquitous diseases and is characterized by destruction of connective tissue and dental bone support following an inflammatory response in host secondary to infection by periodontal bacteria (1). The inflammatory response is characterized by nonregulated secretion of inflammatory mediators and destruction of host tissue (2).

Diabetes mellitus is a metabolic disorder characterized by hyperglycemia. The abnormal glucose metabolism results from defects in insulin production or insulin action, or both (2). Diabetes has major repercussions on the health status of the affected, and its prevalence is growing worldwide (3). More than 240 milion people are diabetic and it is estimated that this number will increase by 2 or 3 fold by the next ten years (4). Some of oral diseases and conditions are more prevalent in the patients with diabetes such as periodontal diseases, dental cavities, xerostomia, and recurrent periapical abscess $(5,6)$.

Patients with diabetes are at higher risk for periodontal disease and it is now considered as the sixth complication of diabetes mellitus (7). There are evidences which show the progressive periodontal disease could disrupt blood sugar balance, but it is not known that periodontal diseases could raise blood sugar or

* Corresponding author: Arash Ghanbarzadegan, Student Research Committee, Rafsanjan University of Medical sciences, Rafsanjan, Iran.

E-mail: Arash.Ghanbarzadegan@yahoo.com 
not, maybe this is a common situation among patients that suffer from peiodontal diseases (8). Some of the researches have claimed that pathogenesis of periodontits in diabetes is unclear $(9,10)$. Many studies have addressed the effect of periodontal treatment on glycemic control in patients with diabetes. Despite discrepancy regarding this issue in the scientific literature, it seems that the effect of glycemic control is related to the mode of periodontal therapy (1).

The host defense alterations and the increased levels of proinflammatory mediators in diabetes result in increased periodontal inflammation, and also contribute to poor diabetes metabolic control, explaining in part the bidirectional relationship of these two diseases. Periodontitis is also associated with an increased risk for diabetes complications. It is possible that periodontal diseases may serve as accelerators of insulin resistance, leading to aggravation of glycemic control. There is emerging evidence that periodontal treatment improves glycemic control in patients with type 2 diabetes (3). Control of periodontal infection seems not only important for oral health, but may also improve the overall health of patients with diabetes mellitus (3). The modified inflammation process could be the meeting ground for chronic periodontitis, diabetes, atherosclerosis and obesity (11).

Also, obesity is common world wide and is going to be replaced with malnutrition and infectious disease as one of contributors to poor health. Obesity is defined as body mass index (BMI) of $30 \mathrm{~kg} / \mathrm{m}^{2}$ or greater (12).

There are controversies about the relation between obesity and periodontal disease. Periodontitis and obesity are among the most common chronic disorders worldwide. Some of the studies reported a positive relation between overweight and periodontal disease $(13,14)$ A recent review suggests that overweight, obesity, weight gain, and increased waist circumference may be risk factors for development of periodontitis or worsening of periodontal measures (15), while others do not mention any significant relation or mention no relation between obesity and periodontal disease $(16,17)$.

Obesity is a risk factor for diabetes and many other diseases. The body mass index is closely related to both percentage body fat and total body fat accumulated in adipocytes and there is an interrelation between blood glucose, lipoprotein, total cholesterol, high-density lipoprotein cholesterol (HDL-C), low-density lipoprtein cholesterol (LDL-C), very lowdensity lipoprotein cholesterol (VLDL-C) and triglyceride levels (18).

Therefore, there is a need to control conventional risk factors for diabetes, including oral health measures and the periodontal disease and it seems to be necessary to have more researches about the relation of diabetes and periodontal disease. The aim of this study was to compare periodontal parameters with the metabolic sugar levels of diabetic and non-diabetic individuals and determine whether a correlation between severity of disease and periodontal status exists.

\section{Materials and Methods}

This cross-sectional study was performed to compare periodontal parameters between patients with diabetes and healthy subjects. In this study, according to other studies and statistical calculation, 56 volunteers were selected with diagnosis of either type 1 or type 2 diabetes by endocrinologist in the endocrine department of city hospital. The patients with diabetes were devided into two groups of type 1 and 2. The control group consisted of 28 healthy individuals without any systemic condition that could affect periodontal status. The inclusion criteria for the study were having at least 15 teeth, and having diabetes for at least five years. The exclusion criteria of the study were using drugs and medications that affected periodontium (tetracycline, antiinflammatory, antiepileptic, etc.) during the last three months, having other systemic diseases or conditions that affects the periodontium (cardiovascular diseases, 
pregnancy, smocking, etc.), receiving treatment for periodontal disease in the past six months, and smoking. After obtaining an informed written consent form all participants in the study, patients' general informations were collected. In the patients with diabetes, disease informations including duration of diabetes and $\mathrm{HbA1c}$ values were obtained through questioning the patients and reviewing their lab tests. BMI was calculated by the weight divided to square of the height and expressed as $\mathrm{kg} / \mathrm{m}^{2}$ unit. Periodontal examinations included evaluation of plaque index (PI), bleeding points index (BPI), clinical attachment loss (CAL) and periodontal pocket depth (PPD) and were obtained using the coded Williams periodontal probe No. 14 (Delab, Treffurt, Germany).

The amount of dental plaques was measured according to the plaque index of Silness and Löe in four regions (mesiobuccal, distobuccal, midbuccal and midlingual) (19).

Because of evaluating plaque thickness in the cervical region of the teeth and ignoring the extent of coronary plaque on the tooth, the Silness and Löe PI is unique among the PIs that have been introduced. An oral mirror, dental explorer and air syringe were used to evaluate the plaque. PI for each region was obtained through the evaluation of four plaque scales for each tooth (disto-facial, facial, mesio-facial and lingual surfaces), and the plaque index for each tooth was calculated by division of total plaque scales for each tooth to four. PI in each individual was obtained by deviding total plaque index of each tooth to the number of teeth examined. The BPI by Ainamo and Bay has been designed and introduced as an easy and convenient tactic for examiners to assess a person's medical progress in controlling plaque. Presence or absence of gingival bleeding was determined by gently probing the gingival sulcus using a periodontal probe. Bleeding after 30 seconds, indicates a positive result which is expressed as a percentage of the total tested gingival margins (20).
Bleeding during probing by touching the sulcus surface or periodontal pocket was determined as the percentage of bleeding area to the total area (21). Bleeding during probing is a major factor for investigating the periodontal health status (22). Application of gingival bleeding indices is an appropriate practice, because hemorrhage is a more clear visual sign than color changes of the gingiva, also because it demonstrates signs of new plaque formation and inflammation in the area and displays attachment loss which is suitable and is used for evaluating the effects of subgingival periodontal therapy (20).

Assessment of CAL from the cemento enamel junction (CEJ) to the depth of pockets and also assessing the extent of the pocket depth was done using the Williams probe No. 14 (Delab, Treffurt, Germany) with gentle pressure from the gingival margin to the bottom of the pocket for the two quadrants of maxilla and mandible in a random matter and in the form of quadrants one and three (upper right, lower left) and two and four (upper left, bottom right). This was calculated in six points: mesio buccal, mid buccal, disto buccal, mesio lingual, mid lingual and disto lingual (23).

After collecting the required data, the data was extracted and analyzed. The information from the questionnaires were analyzed using the SPSS (version 20.0, SPSS Inc., Chicago, IL, USA).

Results of quantitative variables were reported as "mean \pm standard deviations (SD)" and "median (third quartile, first quartile)" and qualitative variables were reported as "number (percent)". In order to compare the mean of quantitative variables examined in the three groups, the one-way analysis of variance (ANOVA) test and in the case of a significant ANOVA result, the least significant difference (LSD) test for multiple comparisons were used. Also, The Kruskal-Wallis $\mathrm{H}$ test was used to compare the median of the quantitative variables in the groups, and in the case of a significant result the non-parametric test Mann-Whitney $U$ test with the Bonferroni correction was used for paired comparisons. 
To compare qualitative variables among the three groups the chi-square test was used. To evaluate the association between periodontal parameters and quantitative factors in the diabetic petiants, Pearson correlation test was used. The significance level of the test (Pvalue) was set at 0.05 .

\section{Results}

This study consisted of two experimental group of type 1 diabetes, type 2 diabetes and control group of 28 healty individuals. The type 1 diabetes group included 15 females $(53.6 \%)$ and $13(46.1 \%)$ males. The type 2 diabetes and the control group both had 19 $(67.9 \%)$ females and $9(32.1 \%)$ males. The comparison of demographic information and periodontal variables in the two diabetic groups and the control group are shown in table 1 .

Table 1: The comparison of base line characteristics and periodontal variables in experimental and control groups

\begin{tabular}{|c|c|c|c|c|c|c|c|}
\hline \multirow[b]{2}{*}{ Variable } & \multicolumn{3}{|c|}{ Study groups } & \multirow[b]{2}{*}{ P-value } & \multicolumn{3}{|c|}{ Comparison of paired groups (P-value) } \\
\hline & $\begin{array}{c}\text { Diabetes } \\
\text { type } 1 \\
(\mathrm{n}=28)\end{array}$ & $\begin{array}{c}\text { Diabetes } \\
\text { type } 2(\mathrm{n}= \\
28)\end{array}$ & $\begin{array}{l}\text { Healthy } \\
\text { individuals } \\
(\mathrm{n}=28)\end{array}$ & & $\begin{array}{c}\text { Diabetes } \\
\text { type } 1 \\
\text { and } 2\end{array}$ & $\begin{array}{c}\text { Diabetes } \\
\text { type } 1 \text { and } \\
\text { healthy } \\
\text { individual }\end{array}$ & $\begin{array}{c}\text { Diabetes } \\
\text { type } 2 \text { and } \\
\text { healthy } \\
\text { individual }\end{array}$ \\
\hline $\begin{array}{c}\text { BMI } \\
\left(\mathrm{kg} / \mathrm{m}^{2}\right)\end{array}$ & $\begin{array}{c}24.50 \pm \\
3.22\end{array}$ & $29.20 \pm 4.63$ & $\begin{array}{c}22.79 \pm \\
4.65\end{array}$ & $<0.001 *$ & $<0.001 *$ & 0.13 & $<0.001 *$ \\
\hline $\begin{array}{l}\text { Number of } \\
\text { lost teeth }\end{array}$ & $1.5(0,3)$ & $5.5(3,10)$ & $2(0,8.25)$ & $<0.001 *$ & $<0.001 *$ & 0.31 & $0.008^{*}$ \\
\hline PPD (mm) & $1.82 \pm 0.34$ & $2.47 \pm 0.66$ & $1.89 \pm 0.59$ & $<0.001 *$ & $<0.001 *$ & 0.65 & $<0.001 *$ \\
\hline PI $(\%)$ & $\begin{array}{c}98.0 \\
(92.5,100)\end{array}$ & $\begin{array}{c}98.6 \\
(93.4,100)\end{array}$ & $\begin{array}{c}81.4 \\
(68.8,95.3)\end{array}$ & $<0.001^{*}$ & 0.88 & $<0.001 *$ & $<0.001 *$ \\
\hline $\mathrm{BI}(\%)$ & $44.8 \pm 13.5$ & $39.04 \pm 17.9$ & $33.8 \pm 15.6$ & $0.04 *$ & 0.17 & $0.01 *$ & 0.210 \\
\hline CAL $(\mathrm{mm})$ & $4.24 \pm 1.80$ & $4.13 \pm 1.67$ & $2.07 \pm 1.65$ & $<0.001 *$ & 0.81 & $<0.001^{*}$ & $<0.001 *$ \\
\hline Sex & - & - & - & 0.441 & - & - & - \\
\hline Female & $15(53.6)$ & $19(67.9)$ & $19(67.9)$ & - & - & - & - \\
\hline Male & $13(46.1)$ & $9(32.1)$ & $9(32.1)$ & - & - & - & - \\
\hline Quadrant & - & - & - & 0.39 & - & - & - \\
\hline $\begin{array}{l}\text { First and } \\
\text { third }\end{array}$ & $14(50.0)$ & $11(39.3)$ & $9(32.1)$ & - & - & - & - \\
\hline $\begin{array}{l}\text { Second } \\
\text { and fourth }\end{array}$ & $14(50.0)$ & $17(60.7)$ & $19(67.9)$ & - & - & - & - \\
\hline
\end{tabular}

BMI: Body mass index; PPD: Periodontal pocket depth; PI: Plaque index; BI: Bleeding index; CAL: Clinical attachment loss *Difference was significant

BMI and also PI was higher in the diabetic groups in comparison to the healthy population and this difference was significant $(\mathrm{P}<0.001)$.

The mean number of lost teeth and the mean PPD was higher in the type 2 diabetes group when compared to the other groups $(\mathrm{P}<0.001)$. The mean bleeding index was higher in the type 1 and 2 diabetes group than the healthy group $(\mathrm{P}=0.036)$. The mean $\mathrm{CAL}$ was also higher in the patients with diabetes $(\mathrm{P}<$ $0.001)$.

The relationship between the studied variables in the type 1 diabetes group is demonstrated in table 2. 
Table 2: The relationship between the studied variables in the type 1 diabetics group

\begin{tabular}{|c|c|c|c|c|c|c|c|c|}
\hline Variable & $\begin{array}{c}\text { Age } \\
\text { (years) }\end{array}$ & $\begin{array}{c}\text { Disease } \\
\text { duration } \\
\text { (years) }\end{array}$ & $\begin{array}{c}\text { HbAlc } \\
(\%)\end{array}$ & $\begin{array}{c}\text { BMI } \\
\left(\mathrm{kg} / \mathrm{m}^{2}\right)\end{array}$ & $\begin{array}{c}\text { Number } \\
\text { of lost } \\
\text { teeth }\end{array}$ & $\begin{array}{l}\text { PPD } \\
(\mathrm{mm})\end{array}$ & PI (\%) & BI (\%) \\
\hline $\begin{array}{c}\text { Disease } \\
\text { duration } \\
\text { (years) }\end{array}$ & $\begin{array}{l}r=0.36 \\
P=0.06\end{array}$ & & & & & & & \\
\hline $\begin{array}{c}\text { HbA1c } \\
(\%)\end{array}$ & $\begin{array}{l}r=0.20 \\
P=0.32\end{array}$ & $\begin{array}{l}r=0.08 \\
P=0.70\end{array}$ & & & & & & \\
\hline $\begin{array}{c}\text { BMI } \\
\left(\mathrm{kg} / \mathrm{m}^{2}\right)\end{array}$ & $\begin{array}{l}r=0.17 \\
P=0.39\end{array}$ & $\begin{array}{l}r=-0.02 \\
P=0.90\end{array}$ & $\begin{array}{l}r=0.35 \\
P=0.07\end{array}$ & & & & & \\
\hline $\begin{array}{c}\text { Number } \\
\text { of lost } \\
\text { teeth }\end{array}$ & $\begin{array}{c}r=0.68 \\
P<0.001\end{array}$ & $\begin{array}{l}r=0.26 \\
P=0.19\end{array}$ & $\begin{array}{l}r=0.44 \\
P=0.02\end{array}$ & $\begin{array}{l}r=0.35 \\
p=0.07\end{array}$ & & & & \\
\hline $\begin{array}{l}\text { PPD } \\
(\mathrm{mm})\end{array}$ & $\begin{array}{l}r=0.37 \\
P=0.05\end{array}$ & $\begin{array}{l}r=0.38 \\
P=0.05\end{array}$ & $\begin{array}{l}r=0.09 \\
P=0.64\end{array}$ & $\begin{array}{l}r=0.01 \\
P=0.95\end{array}$ & $\begin{array}{l}r=0.15 \\
P=0.45\end{array}$ & & & \\
\hline PI (\%) & $\begin{array}{l}r=-0.31 \\
P=0.11\end{array}$ & $\begin{array}{l}r=-0.04 \\
P=0.84\end{array}$ & $\begin{array}{l}r=-0.29 \\
P=0.14\end{array}$ & $\begin{array}{l}r=-0.20 \\
P=0.31\end{array}$ & $\begin{array}{l}r=-0.14 \\
P=0.47\end{array}$ & $\begin{array}{l}r=0.15 \\
P=0.46\end{array}$ & & \\
\hline BI (\%) & $\begin{array}{l}r=-0.58 \\
P=0.001\end{array}$ & $\begin{array}{l}r=-0.12 \\
P=0.55\end{array}$ & $\begin{array}{l}r=-0.09 \\
P=0.64\end{array}$ & $\begin{array}{l}r=-0.25 \\
P=0.21\end{array}$ & $\begin{array}{l}r=-0.40 \\
P=0.04\end{array}$ & $\begin{array}{l}r=-0.02 \\
P=0.93\end{array}$ & $\begin{array}{l}\mathrm{r}=0.37 \\
\mathrm{P}=0.06\end{array}$ & \\
\hline $\mathrm{CAL}(\mathrm{mm})$ & $\begin{array}{l}r=-0.08 \\
P=0.70\end{array}$ & $\begin{array}{l}r=0.13 \\
P=0.45\end{array}$ & $\begin{array}{l}r=-0.30 \\
P=0.13\end{array}$ & $\begin{array}{l}r=-0.06 \\
P=0.75\end{array}$ & $\begin{array}{l}r=-0.30 \\
P=0.13\end{array}$ & $\begin{array}{l}r=0.28 \\
P=0.15\end{array}$ & $\begin{array}{l}r=0.13 \\
P=0.53\end{array}$ & $\begin{array}{l}\mathrm{r}=-0.02 \\
\mathrm{P}=0.94\end{array}$ \\
\hline
\end{tabular}

BMI: Body mass index; PPD: Periodontal pocket depth; PI: Plaque index; BI: Bleeding index; CAL: Clinical attachment loss $(\mathrm{P}<0.05)$

Statistical analysis showed a meaningful relationship between $\mathrm{BMI}$ and the $\mathrm{BPI}(\mathrm{P}=$ 0.21 and $\mathrm{r}=0.245)$.

Also, results showed a significant relationship between the number of lost teeth with three variables of $\mathrm{HbA}_{1} \mathrm{c}$ and $\mathrm{BMI}(\mathrm{P}=0.02$ and $\mathrm{r}=$ $0.44, \mathrm{P}=0.07$ and $\mathrm{r}=0.35$, respectively).

The relationship among the variables studied in the type 2 diabetes group is provided in table 3 .

Table 3: The relationship among the variables studied in the type 2 diabetes group

\begin{tabular}{|c|c|c|c|c|c|c|c|c|}
\hline Variable & $\begin{array}{c}\text { Age } \\
\text { (years) }\end{array}$ & $\begin{array}{c}\text { Disease } \\
\text { duration } \\
\text { (years) }\end{array}$ & $\begin{array}{c}\text { HbAlc } \\
(\%)\end{array}$ & $\begin{array}{c}\text { BMI } \\
\left(\mathrm{kg} / \mathrm{m}^{2}\right)\end{array}$ & $\begin{array}{c}\text { Number } \\
\text { of lost } \\
\text { teeth }\end{array}$ & $\begin{array}{l}\text { PPD } \\
(\mathrm{mm})\end{array}$ & PI (\%) & BI (\%) \\
\hline $\begin{array}{c}\text { Disease } \\
\text { duration } \\
\text { (years) }\end{array}$ & $\begin{array}{l}r=0.29 \\
P=0.13\end{array}$ & & & & & & & \\
\hline HbA1c (\%) & $\begin{array}{l}r=-0.38 \\
P=0.05\end{array}$ & $\begin{array}{l}r=0.16 \\
P=0.42\end{array}$ & & & & & & \\
\hline $\begin{array}{c}\text { BMI } \\
\left(\mathrm{kg} / \mathrm{m}^{2}\right) \\
\end{array}$ & $\begin{array}{l}r=-0.08 \\
P=0.69\end{array}$ & $\begin{array}{l}r=0.04 \\
P=0.84\end{array}$ & $\begin{array}{l}r=0.20 \\
P=0.30\end{array}$ & & & & & \\
\hline $\begin{array}{l}\text { Number of } \\
\text { lost teeth }\end{array}$ & $\begin{array}{l}\mathrm{r}=-0.01 \\
\mathrm{P}=0.98\end{array}$ & $\begin{array}{l}\mathrm{r}=0.50 \\
\mathrm{P}=0.01\end{array}$ & $\begin{array}{l}\mathrm{r}=0.16 \\
\mathrm{P}=0.41\end{array}$ & $\begin{array}{l}\mathrm{r}=0.09 \\
\mathrm{P}=0.64\end{array}$ & & & & \\
\hline PPD (mm) & $\begin{array}{l}r=-0.06 \\
P=0.76\end{array}$ & $\begin{array}{l}\mathrm{r}=-0.21 \\
\mathrm{P}=0.28\end{array}$ & $\begin{array}{l}\mathrm{r}=0.28 \\
\mathrm{P}=0.15\end{array}$ & $\begin{array}{l}\mathrm{r}=0.11 \\
\mathrm{P}=0.59\end{array}$ & $\begin{array}{l}r=-0.08 \\
P=0.67\end{array}$ & & & \\
\hline PI (\%) & $\begin{array}{l}\mathrm{r}=-0.17 \\
\mathrm{P}=0.39\end{array}$ & $\begin{array}{l}r=-0.03 \\
P=0.89\end{array}$ & $\begin{array}{l}r=-0.28 \\
P=0.15\end{array}$ & $\begin{array}{l}r=0.03 \\
P=0.89\end{array}$ & $\begin{array}{l}\mathrm{r}=0.05 \\
\mathrm{P}=0.82\end{array}$ & $\begin{array}{l}\mathrm{r}=0.12 \\
\mathrm{P}=0.56\end{array}$ & & \\
\hline $\mathrm{BI}(\%)$ & $\begin{array}{l}r=-0.07 \\
P=0.73\end{array}$ & $\begin{array}{l}\mathrm{r}=0.02 \\
\mathrm{P}=0.93\end{array}$ & $\begin{array}{c}r=-0.001 \\
P=0.99\end{array}$ & $\begin{array}{l}r=0.09 \\
P=0.63\end{array}$ & $\begin{array}{l}\mathrm{r}=0.03 \\
\mathrm{P}=0.88\end{array}$ & $\begin{array}{l}\mathrm{r}=0.15 \\
\mathrm{P}=0.45\end{array}$ & $\begin{array}{l}\mathrm{r}=0.14 \\
\mathrm{P}=0.49\end{array}$ & \\
\hline $\mathrm{CAL}(\mathrm{mm})$ & $\begin{array}{l}r=0.29 \\
P=0.13\end{array}$ & $\begin{array}{l}\mathrm{r}=-0.02 \\
\mathrm{P}=0.92\end{array}$ & $\begin{array}{l}r=-0.10 \\
P=0.61\end{array}$ & $\begin{array}{l}r=-0.22 \\
P=0.26\end{array}$ & $\begin{array}{l}r=0.29 \\
P=0.14\end{array}$ & $\begin{array}{l}\mathrm{r}=0.23 \\
\mathrm{P}=0.24\end{array}$ & $\begin{array}{l}\mathrm{r}=0.10 \\
\mathrm{P}=0.63\end{array}$ & $\begin{array}{l}r=-0.03 \\
P=0.89\end{array}$ \\
\hline
\end{tabular}

BMI: Body mass index; PPD: Periodontal pocket depth; PI: Plaque index; BI: Bleeding index; CAL: Clinical attachment loss 
A significant relationship was found between the duration of sickness and the number of lost teeth $(\mathrm{P}=0.01$ and $\mathrm{r}=0.50)$. The relationship among the variables studied in the healthy group is provided in table 4. A significant relationship was found between $\mathrm{BMI}$ and the number of lost teeth $(\mathrm{P}=0.08$ and $\mathrm{r}=0.34)$.

Table 4: The relationship among the variables studied in the healthy group

\begin{tabular}{|c|c|c|c|c|c|c|}
\hline Variable & Age (years) & $\begin{array}{c}\text { BMI } \\
\left(\mathrm{kg} / \mathrm{m}^{2}\right)\end{array}$ & $\begin{array}{c}\text { Number of } \\
\text { lost teeth }\end{array}$ & PPD (mm) & PI $(\%)$ & BI (\%) \\
\hline BMI $\left(\mathrm{kg} / \mathrm{m}^{2}\right)$ & $\begin{array}{l}r=0.34 \\
P=0.08\end{array}$ & & & & & \\
\hline $\begin{array}{l}\text { Number of } \\
\text { lost teeth }\end{array}$ & $\begin{array}{c}r=0.68 \\
P<0.001\end{array}$ & $\begin{array}{l}r=0.34 \\
P=0.8\end{array}$ & & & & \\
\hline PPD (mm) & $\begin{array}{l}\mathrm{r}=0.37 \\
\mathrm{P}=0.05\end{array}$ & $\begin{array}{l}r=0.11 \\
P=0.57\end{array}$ & $\begin{array}{l}r=0.15 \\
P=0.46\end{array}$ & & & \\
\hline PI (\%) & $\begin{array}{l}\mathrm{r}=-0.05 \\
\mathrm{P}=0.82\end{array}$ & $\begin{array}{l}\mathrm{r}=0.23 \\
\mathrm{P}=0.24\end{array}$ & $\begin{array}{l}\mathrm{r}=0.03 \\
\mathrm{P}=0.90\end{array}$ & $\begin{array}{l}\mathrm{r}=0.18 \\
\mathrm{P}=0.35\end{array}$ & & \\
\hline BI (\%) & $\begin{array}{l}r=0.27 \\
P=0.17\end{array}$ & $\begin{array}{l}r=0.02 \\
P=0.94\end{array}$ & $\begin{array}{l}\mathrm{r}=0.19 \\
\mathrm{P}=0.34\end{array}$ & $\begin{array}{c}r=0.61 \\
P=0.001\end{array}$ & $\begin{array}{l}\mathrm{r}=0.13 \\
\mathrm{P}=0.50\end{array}$ & \\
\hline CAL (mm) & $\begin{array}{l}\mathrm{r}=0.23 \\
\mathrm{P}=0.23\end{array}$ & $\begin{array}{l}\mathrm{r}=0.07 \\
\mathrm{P}=0.73\end{array}$ & $\begin{array}{l}\mathrm{r}=0.31 \\
\mathrm{P}=0.11\end{array}$ & $\begin{array}{l}r=0.39 \\
P=0.04\end{array}$ & $\begin{array}{l}r=-0.09 \\
P=0.65\end{array}$ & $\begin{aligned} r & =0.53 \\
P & =0.004\end{aligned}$ \\
\hline
\end{tabular}

BMI: Body mass index; PPD: Periodontal pocket depth; PI: Plaque index; BI: Bleeding index; CAL: Clinical attachment loss

\section{Discussion}

Diabetes mellitus (DM) is a metabolic disease characterized by an increased blood glucose level, while periodontal disease is mainly characterized by the destruction of tooth support tissues. Detailed investigation is warranted to consider these highly prevalent chronic diseases together and analyze their mutual influence. The goal of this study was to compare the periodontal parameters of patients with diabetes type 1 and 2 with healthy people. The diabetic group in comparison to the observation group was in a worse condition, in other words the diabetic group showed a higher level of plaque, bleeding during probing, number of lost teeth, PPD and CAL in comparison to the healthy group $(\mathrm{P}<0.05)$. The average PI in patients with diabetes type 1 and 2 was more than that of the healthy group which can indicate a lower quality of oral hygiene in diabetics. Sastrowijoto et al. in 1990 concluded that the lower dental and oral quality in patients with diabetes was the reason for a worse periodontal condition (24). With regard to bleeding index, the increase of the bleeding index in patients with diabetes can be related to the fact that a high percentage of patients with diabetes were on medications, such as Metformin, that lower the blood glucose levels and have a combined anticoagulant effect. Other studies like the study by Cabala et al. in 2006, have shown a higher bleeding rate during probing in patients with diabetes in comparison to healthy patients (25).

Over the years, various biologically plausible mechanisms have been established for a common inflammatory etiopathogenesis of these diseases (2). Inflammation is the central feature of the pathogenesis of both DM and periodontal disease. As one of the principal defense mechanisms, inflammation should work smoothly to protect adequately. If it is modified or altered in any way, it might become a trigger mechanism started by a pathogenic aggression that could explain the onset of a disease (11). This elevated inflammatory state contributes to macro- and micro-vascular complications and clinical manifestations like bleeding. Diabetes is known to increase inflammation in periodontal 
tissues. Thus, gingival crevicular fluid (GCF) levels of prostaglandin E2 (PGE2) and interleukin-1 $\beta$ (IL-1 $\beta$ ) are higher in patients with type 1 diabetes and gingivitis or periodontitis than in non-diabetic individuals with the same degree of periodontal disease. One study found significantly higher GCF and IL-1 $\beta$ levels in patients with diabetes type 2 who had HbA1c of higher than $8 \%$ than in those with $\mathrm{HbA} 1 \mathrm{c}<8 \%$, suggesting that $\mathrm{HbA1c}$ and glucose levels were independent predictors of elevated GCF and IL- $1 \beta$ levels $(26,27)$.

The average CAL in patients with diabetes type 1 and 2 was higher than the healthy group which can indicate that an increase in CAL was more common in the diabetes group in comparison to the healthy group and this is consistent with the results of Tomita NE et al. in 2002 (28).

The average pocket depth in the type 2 diabetic group was more than that of the healthy group which can indicate a significant relationship between the increase of pocket depth due to periodontal disease in patients with diabetes type 2 .

In the type 1 diabetic group there was a meaningful relationship between pocket depth and the disease duration index which could be due to the negative effect of the duration of diabetes on the increasing of pocket depth. Our findings were in coherence with the study by Tervoan and Oliver in 1993, that claimed periodontitis in diabetics is associated with long term metabolic status and existense of calculus (29).

It was reported that the tissue damage by Porphyromonas gingivalis inoculation resulted in a higher percentage of fibroblast apoptosis in diabetic mice than in controls, indicating a further mechanism by which diabetes may interfere in the repairing capacity of inflamed periodontal tissues (27).

A recent study from analyzing National Health and Nutrition Examination Survey data demonstrated that glycohemoglobin and demographic factors were significantly associated with periodontitis (30). In present study, the relation between blood glucose level and periodontal parameters have been studied. There was a meaningful relationship between the number of lost teeth and the increased $\mathrm{HbA}_{1} \mathrm{c}$ level in patients with diabetes type 1 . These results are similar to findings reported in other studies. Jansson in 2006 showed that the periodontal conditions were worse in patients with diabetes who had a higher level of $\mathrm{HbA}_{1} \mathrm{c}(31)$.

In the type 2 diabetEs group, there was also a meaningful relationship between the number of lost teeth and the disease duration indicating that the periodontal status worsens as the duration of the disease progresses. The average number of lost teeth in the type 2 diabeties group was higher than the healthy group which can indicate a significant relation between the number of lost teeth due to periodontal diseases in patients with diabetes type 2. Our results are consistent with the results of Ilguy's study in 2007 (32).

Periodontitis induces endotoxiemia and is responsible for increased levels of cytokines such as interleukin (IL-1 $\beta$ ) and tumor necrosis factor alpha (TNF- $\alpha$ ) and leads to alteration in lipid metabolism. Periodontitis is responsible for producing cytokines which may develop insulin resistance similar to DM and which may destroy Beta cells of pancreas which leads to development of DM (18).

The average BMI in patients with diabetes type 1 and 2 was higher than the healthy group which indicates that being overweight was more common in the patient groups. On the other hand, BMI was associated with higher level of parameters, so it could be a common risk factor for both periodontal disease and diabetes. Hasegawa and Watase in 2004 concluded that life style factors have an important association with periodontal diseases (33).

Several explanations have been provided for the association between obesity and periodontal disease such as low raw fruit and non-potato vegetables intake, which are sources of vitamin $\mathrm{C}$, and low calcium intake as well as higher intake of soft drinks and 
noncitrus juices (1). This is important to oral health because low dietary intake of calcium and vitamin $\mathrm{C}$ has been associated with periodontal disease. People who consume less than the recommended dietary allowance (RDA) of calcium and vitamin $\mathrm{C}$ have slightly higher rates of periodontal disease (1).

BMI is closely related to both percentage body fat and total body fat accumulated in adipocytes. Data obtained from Panwar et al. study revealed that there was an interrelation between blood glucose, lipoproteins and triglyceride levels (18). It has been found that adipokines can also contribute to susceptibility to both periodontitis and DM, and the proinflammatory properties of leptin may be especially important in the overexpression of periodontal tissue inflammation in individuals with obesity and type 2 diabetes $(26,27)$.

As we know, DM is a life threatening metabolic syndrome and periodontitis is an infectious disease and responsible for destruction of systemic physiology not only in patients with diabetes but also in non-diabetic population all over the world. We recommend to carry out a study by collecting oral bacterial samples from patients and examining hidden dental and gum disorders by acquiring dental graphs and also conducting prospective and retrospective studies regarding the association between periodontal diseases and diabetes to evaluate the cause and effect of this factor.

\section{Conclusion}

Based on the results gained from this study, most of the periodontal indices (plaque index, bleeding index and clinical attachment loss) were higher in patients with diabetes than healthy people which can be an indicator of an association between diabetes and periodontal diseases. In patients with diabetes type 2, there was a significant relationship between the number of lost teeth and the duration of disease which indicates that the periodontal status worsens as the duration of disease progresses. Also, we found a significant relationship between BMI index and level of
$\mathrm{HbA}_{1} \mathrm{c}$ and some periodontal indices in this study.

\section{Acknowledgments}

We are thankful to all participants for their collaboration.

Conflict of interest: None declared.

\section{References}

1- AlJehani YA. Risk factors of periodontal disease: review of the literature. Int J Dent 2014; 2014:182513.

2- Bascones A, González J, Sanz J. Diabetes and periodontal disease. Review of the literature. Am J Dent 2014; 27(2):63-7.

3- Stanko P, Izakovicova Holla L. Bidirectional association between diabetes mellitus and inflammatory periodontal disease. A review. Biomed Pap Med Fac Univ Palacky Olomouc Czech Repub 2014; 158(1):35-8.

4- Geiss LS, Pan L, Cadwell B, Gregg EW, Benjamin SM, Engelgau MM. Changes in incidence of diabetes in US adults, 1997-2003. Am J Prev Med 2006; 30(5):371-7.

5- Campus G, Salem A, Uzzau S, Baldoni E, Tonolo G. Diabetes and periodontal disease: a case-control study. J Periodontol 2005; 76(3):418-25.

6- Lalla E, Park DB, Papapanou PN, Lamster IB. Oral disease burden in Northern Manhattan patients with diabetes mellitus. Am J Public Health 2004; 98(Suppl 1):S91-4.

7- Löe H. Periodontal disease: the sixth complication of diabetes mellitus. Diabetes Care 1993; 16(1):329-34.

8- Lösche W, Karapetow F, Pohl A, Pohl C, Kocher T. Plasma lipid and blood glucose levels in patients with destructive periodontal disease. J Clin Periodontol 2000; 27(8):537-41.

9- Shoelson SE, Lee J, Goldfine AB. Inflammation and insulin resistance. J Clin Invest 2006; 116(7):1793-801.

10- Hayden P, Buckley LA. Diabetes mellitus and periodontal disease in an Irish population. J Periodontal Res 1989; 24(5):298-302.

11- Bullon P, Newman HN, Battino M. Obesity, diabetes mellitus, atherosclerosis and chronic periodontitis: a shared pathology via oxidative stress and mitochondrial dysfunction? Periodontol 2000; 64(1):139-53.

12- Calle EE, Rodriguez C, Walker-Thurmond K, Thun MJ. Overweight, obesity, and mortality 
from cancer in a prospectively studied cohort of US adults. N Engl J Med 2003; 348(17):1625-38.

13- Genco RJ, Grossi SG, Ho A, Nishimura F, Murayama Y. A proposed model linking inflammation to obesity, diabetes, and periodontal infections. J Periodontol 2005; 76(11 Suppl):2075-84.

14- Dalla Vecchia CF, Susin C, Rösing CK, Oppermann RV, Albandar JM. Overweight and obesity as risk indicators for periodontitis in adults. J Periodontol 2005; 76(10):1721-8.

15- Keller A, Rohde JF, Raymond K. Association between periodontal disease and overweight and obesity: a systematic review. J Periodontol 2015; 86(6):766-76.

16- Al-Zahrani MS, Bissada NF, Borawskit EA. Obesity and periodontal disease in young, middle-aged, and older adults. J Periodontol 2003; 74(5):610-5.

17- Nishida N, Tanaka M, Hayashi N, Nagata H, Takeshita T, Nakayama K, et al. Determination of smoking and obesity as periodontitis risks using the classification and regression tree method. J Periodontol 2005; 76(6):923-8.

18- Panwar SKh, Bhargava AK, Pandey I. Correlation between periodontal disease and diabetes mellitus. Indian Journal of Applied Research 2015; 5(10):202-3.

19- Pontes Andersen CC, Flyvbjerg A, Buschard K, Holmstrup P. Relationship between periodontitis and diabetes: lessons from rodent studies. J Periodontol 2007; 78(7):1264-75.

20- Carranza FA, Newman MG. Clinical periodontology. $8^{\text {th }}$ ed. Philadelphia, United States: Walter Burns Saunders Co; 1996. P. 6177.

21- Newman MG, Takei H, Klokkevold PR, Carranza FA. Carranza's clinical periodontology. $10^{\text {th }}$ ed. Philadelphia, United States: Walter Burns Saunders Co Ltd; 2006. P.728-48

22- Armitage GC. Periodontal diseases: diagnosis. Ann Periodontol 1996; 1(1):37-215.

23- Vettore MV, Lamarca Gde A, Leão AT, Sheiham A, Leal Mdo C. Partial recording protocols for periodontal disease assessment in epidemiological surveys. Cad Saude Publica 2007; 23(1):33-42.

24- Sastrowijoto SH, van der Velden U, van Steenbergen TJ, Hillemans P, Hart AA, de Graaff J, et al. Improved metabolic control, clinical periodontal status and subgingival microbiology in insulin- dependent diabetes mellitus. J Clin Periodontol 1990; 17(4):23342.

25- Cabała A, Chomyszyn-Gajewska M, Drozdz W. Periodontitis and systemic disease relationships. Przegl Lek 2006; 63(9):773-7.

26- Preshaw PM, Alba AL, Herrera D, Jepsen S, Konstantinidis A, Makrilakis $\mathrm{K}$, et al. Periodontitis and diabetes: a two-way relationship. Diabetologia 2012; 55(1):21-31.

27- Taylor JJ, Preshaw PM, Lalla E. A review of the evidence for pathogenic mechanisms that may link periodontitis and diabetes. J Periodontol 2013; 84(4 Suppl):S113-34.

28- Tomita NE, Chinellato LE, Pernambuco RA, Lauris JR, Franco LJ; Grupo de Estudo Diabetes em Nipo-Brasileiros. Periodontal conditions and diabetes mellitus in the Japanese-Brazilian population. Rev Saude Publica 2002; 36(5):607-13.

29- Tervonen T, Oliver RC. Long-term control of diabetes mellitus and periodontitis. J Clin Periodontol 1993; 20(6):431-5.

30- Garcia D, Tarima S, Okunseri C. Periodontitis and glycemic control in diabetes: NHANES 2009 to 2012. J Periodontol 2015; 86(4):499506.

31- Jansson H, Lindholm E, Lindh C, Groop L, Bratthall G. Type 2 diabetes and risk for periodontal disease: a role for dental health awareness. J Clin Periodontol 2006; 33(6):40814.

32- Ilgüy M, Ilgüy D, Bayirli G. Dental lesions in adult diabetic patients. N Y State Dent J 2007; 73(1):58-6.

33- Hasegawa T, Watase H. Multiple risk factors of periodontal disease: a study of 9260 Japanese non-smokers. Geriatr Gerontol Int 2004; 4(1):37-43. 